\title{
Correction to: Echinodermata: The Complex Immune System in Echinoderms
}

\author{
L. Courtney Smith, Vincenzo Arizza, Megan A. Barela Hudgell, \\ Gianpaolo Barone, Andrea G. Bodnar, Katherine M. Buckley, \\ Vincenzo Cunsolo, Nolwenn M. Dheilly, Nicola Franchi, \\ Sebastian D. Fugmann, Ryohei Furukawa, Jose Garcia-Arraras, \\ John H. Henson, Taku Hibino, Zoe H. Irons, Chun Li, Cheng Man Lun, \\ Audrey J. Majeske, Matan Oren, Patrizia Pagliara, Annalisa Pinsino, \\ David A. Raftos, Jonathan P. Rast, Bakary Samasa, \\ Domenico Schillaci, Catherine S. Schrankel, Loredana Stabili, \\ Klara Stensväg, and Elisse Sutton
}

\section{Correction to:}

Chapter 13 in: E. L. Cooper (ed.), Advances in Comparative Immunology, https://doi.org/10.1007/978-3-319-76768-0_13

This chapter was inadvertently published with an incorrect spelling of the author's name as V. Arriza whereas it should be V. Arizza.

In addition to this the affiliation of one of the chapter authors Elisse Sutton was published incorrectly and it has now been corrected to read as Department of Biological Sciences, Macquarie University, Sydney, NSW, Australia.

The updated online version of this chapter can be found at https://doi.org/10.1007/978-3-319-76768-0_13 